\title{
Psychological and Physiological Complications of Post-Burn Patients in Pakistan A narrative review
}

Meher B. Ali and *Mashal B. Ali

\begin{abstract}
Pakistan has a burn mortality rate of $6.5 \%$, with a considerable percentage of survivors suffering from long-term complications due to lack of rehabilitation. This review aimed to outline the important physiological and psychological after-effects of burn injuries. Google Scholar, MEDLINE ${ }^{\bullet}$ and PubMed were searched for relevant articles between March and May 2020. Psychological complications of burns include depression, post-traumatic stress disorder, anxiety, sleep disturbance, phobias, guilt, suicidal thoughts and personality changes. Physiological complications include scarring, contractures, pain, muscle wasting and hypothermia; other complications include infections. This review revealed a scarcity of literature regarding the prevalence and impact of long-term complications in post-burn patients. A lack of rehabilitative services and high rate of post-burn complications in Pakistan were found. Rehabilitation of burn patients should be a continuation of active treatment and should begin from the day of admission, to reduce the morbidity and improve the quality of life of burn patients.
\end{abstract}

Keywords: Burns; Physiology; Psychology; Rehabilitation; Quality of Life; Pakistan.

A CCORDING TO WORLD HEALTH ORGANIZATION, burn injuries account for 180,000 deaths annually, with the majority of such injuries occurring in low- and middle-income countries. ${ }^{1}$ Pakistan has a burn mortality rate of $6.5 \%$, with a burns centre in Karachi reporting an exceptionally high mortality rate of $55.9 \%$, which may be due to the lack of adequate infrastructure needed to manage burn patients. ${ }^{2,3}$ However, it is also possible that the more severely affected patients are admitted to the burns centre causing a difference in the general burn mortality rate and the mortality rate in rehabilitation centres. Females, children and people living in poverty are at particular risk for burn injuries and the most common cause of burns are accidental injuries at home or the workplace. ${ }^{1}$ Although these are not usually fatal, they carry a significant morbidity risk. According to a recent study conducted at the Burns Center, Civil Hospital Karachi, almost 94\% of burns were accidental and $1.5 \%$ were suicidal. ${ }^{4}$ Another study reported accidental burns in $83.78 \%$ of their sample while $9.88 \%$ were homicidal and $6.34 \%$ were of a suicidal nature. ${ }^{5}$

Public and private sector hospitals throughout Pakistan face a large influx of burn patients, which places significant burden on the healthcare system. ${ }^{2}$ Despite a decrease in mortality, morbidity from burns is a significant cause of disability-adjusted life-years lost in low- and middle-income countries. ${ }^{1}$ In Pakistan, there is a shortage of burn rehabilitation centres. ${ }^{6}$ Civil Hospital Karachi is the only hospital in the Sindh province that has a burns centre, catering to patients from all parts of the province. ${ }^{7}$ Baluchistan province does not have a single burn rehabilitation centre. Hence, burn victims have no choice but to travel to Karachi for treatment. In a province such as Khyber Pakhtunkhwa, which also caters to patients from tribal areas, the lack of burns centres is a glaring deficiency in its health infrastructure as one of the major burn units after three years of construction remains nonfunctional. ${ }^{8}$ There are only four burn units in Punjab, the most populated province of Pakistan, and most have limited resources and beds. ${ }^{9}$ Rehabilitative medicine is still a relatively new concept in Pakistan; emphasis is only on treating acute injury rather than preventing future complications. ${ }^{10}$ In Pakistan, there is generally a lack of awareness of burn victims and the challenges they have to endure. ${ }^{11}$ The long-term effects are not just limited to the physical complications of burn injuries such as scarring or contractures; they also include the, at times more severe and debilitating, psychological ones (e.g. depression and phobias). Treatment, therapy and effective rehabilitation of burn patients can drastically increase if doctors of Pakistan and other third-world countries become aware of these issues. Physicians must start looking beyond the hospital-confined treatment given to burn patients and start developing insight and sympathy about the future of the patients after they have gone home. This concise literature review aimed to outline the important physiological and psychological after-effects of burn injuries and their risk factors that clinicians must take into account during the treatment, discharge, followup and rehabilitation of burn patients. 
Table 1: Complications in post-burn patients

Post-burn complication
Psychological
Depression"
Post-traumatic stress disorder*
Anxiety"
Sleep disturbance
Phobias
Personality changes
Guilt
Suicidal thoughts
Physiological
Scarring*
Contractures"
Chronic inflammation
Muscle wasting
Hypothermia
Pain
Infection
Other
"Iicates common complication.

\section{Data Collection}

A literature review on the possible complications that occur in burn patients was carried out by a comprehensive search of the databases Google Scholar, PubMed and MEDLINE ${ }^{\circledR}$ between March and May 2020. The search algorithms used were: 'post-burn complications', 'quality of life in burn patients', 'psychological complications in burn patients', 'physiological complications in burn patients', 'rehabilitation of burn patients' and other variations. Relevant publications including literature reviews, systematic reviews, meta-analysis studies, newspaper articles, datasheets and cross-sectional studies published between 1970 and 2020 were included. Only articles written in English were included. Full articles were read after screening the titles and abstracts. Each article was included in the review on the consensus of the authors; finally, a total of 59 articles were included.

\section{Psychological complications}

Psychological problems manifest most visibly 1-4 years after discharge, as discussed in Ter Smitten et al's study. ${ }^{12}$ More than half of diagnosed patients fell within the category of Diagnostic and Statistical Manual of Mental Disorders, $5^{\text {th }}$ Edition Axis I psychiatric disorders (consisting of all disorders except mental retardation and personality disorders) within 2-4 years after the burn injury. ${ }^{12}$

A recent study conducted at a tertiary care burns unit in Karachi reported a depression prevalence of $31.9 \%$ in burn patients. ${ }^{13}$ Depression is a major factor that affects a patient's quality of life. It was found that depression scores remained stable at one month, one year and two years post-burn. ${ }^{13}$ This may also cause reduced body functioning. ${ }^{14}$ The visibility of the burn injury leads to a higher occurrence of depression and feelings of dissatisfaction with facial disfigurement being most valuable in the estimation of psychological outcome. ${ }^{15-17}$ Total body surface area (TBSA) of the burn(s) does not significantly affect depression scores according to a recent study conducted in Pakistan. ${ }^{17}$

Post-traumatic stress disorder (PTSD) has been found in up to $45 \%$ of burn survivors one year after the initial injury. ${ }^{18}$ Talking specifically about Pakistan, in a recent study, more than half of the burn population was found to be suffering from PTSD; these high statistics may be due to stigmatisation and lack of mental health care. ${ }^{19}$ In another study from Pakistan, it was found that PTSD symptoms are more severe in the female population due to decreased resilience among women. ${ }^{20}$ Low socioeconomic condition of the patient is a risk factor for the development of PTSD. ${ }^{21}$ According to Roca et al.s study, individual symptoms of PTSD were more common in post-burn patients than the fully expressed syndrome; however, the prevalence of the complete syndrome has a delayed onset occurring mostly within 3-4 months after discharge. ${ }^{22,23}$ The presenting symptoms include those that meet PTSD criterion C (i.e. emotional numbing and symptoms of avoidance such as an inability to recall events and estrangement from others) and PTSD criterion D (i.e. increased arousals such as heightened irritability and hypervigilance). ${ }^{22}$ PTSD is a greatly neglected sector of medicine and is underdiagnosed by doctors. ${ }^{24}$

In follow-up cases, anxiety is a common presenting complaint; a study showed $37 \%$ of burn patients fell within the criteria of Hospital Anxiety and Depression Scale (HADS). ${ }^{16}$ Patients scoring 8-10 on HADS were regarded as borderline and those scoring more than 11 were regarded as actual cases. Increased size/intensity of burn injury increased the severity of anxiety. ${ }^{16}$ In a recent study conducted in Pakistan, the entire burns patient sample was found to have anxiety, using the Hamilton Anxiety Rating Scale, with severe anxiety more prevalent in deep burn injuries. ${ }^{17}$

Sleep is an important factor in the determination of the effects of a traumatic event on an individual since the quality of sleep is inevitably affected. ${ }^{25}$ Sleep 
disturbance in burn patients consists of lack of deep sleep, nightmares and alterations in sleep patterns and sleep onset. ${ }^{25}$ According to Boeve et al's study, $87 \%$ of burn patients had frequent night-time awakenings. ${ }^{25}$ In Lee et al's study, almost half the patients complained of sleep dissatisfaction 36 months after the injury. ${ }^{26}$

Agoraphobias, with or without panic disorders, and social phobias may also be developed in burn patients, albeit not as much as PTSD, anxiety and depression. They may be found up to $1-2$ years postburn. ${ }^{12}$ The most prevalent among the phobias are specific phobias that manifest after discharge and may increase the comorbidity in burn patients. ${ }^{12}$

Personality changes appearing in burn patients are usually classified as neuropsychiatric complications and may be due to the result of direct hypoxic injury to the brain. ${ }^{27}$ In a study on neuropsychiatric complications in burn patients, it was found that severe regression, a form of personality change, occurs in approximately $20 \%$ of adult burn patients and is characterised by child-like and primitive behaviour patterns such as throwing tantrums. ${ }^{28}$

In a recent systemic review by Kornhaber et al., the feeling of guilt, shame and self-blame were emphasised as important manifesting problems among burn survivors. ${ }^{29}$ One of the most extreme psychological sequelae of burn injuries is suicide. ${ }^{30,31}$

According to Van Loey and Van Son's extensive systemic review, 18 studies showed that previous psychiatric history such as depression, anxiety or mood disorders had the most impact on post-burn mental health changes. Subjective factors such as coping style, personality traits and patient's perception have an effect on post-burn mental health changes. ${ }^{18}$ Social support and family attitude also considerably affect the intensity of psychological sequelae in burn patients, especially in children. ${ }^{32}$ In a study conducted in Pakistan, it was found that social support was extremely lacking in the lives of burn patients, both from family and friends, which undoubtedly hinders the healing process. ${ }^{33}$ The most common form of coping strategy used by burn patients is problemfocused coping which contributes positively to posttraumatic growth such as appreciation of life and personal strength. ${ }^{18,34}$ Problem-focused coping or active coping consists of identifying the stressor, making a plan, taking an action and seeking help/ assistance for instrumental reasons, contributing to a positive change and helping the burn patient in the long-run. ${ }^{35}$ According to Fong's study, women tend to gravitate more towards emotional-coping, which involves seeking social support for moral backing, sympathy and understanding, which possibly may hinder the long-term psychological adjustment if used for too long. ${ }^{35,36}$

\section{Physiological complications}

Scarring is found in all types of burns, except in superficial or first-degree burns, and can only be reduced by measures such as plastic surgery. ${ }^{37}$ According to Gangemi et al's study, the most commonly used method to reduce a burn scar is excision and coverage with autologous skin grafts. ${ }^{38}$ According to a recent systemic review on the incidence of hypertrophic scarring in burn patients, the prevalence of scarring varies from $32-72 \%{ }^{39}$ Keloids are scars that grow and extend beyond the borders of the original burn wound, are often painful and pruritic, and never regress spontaneously; on the other hand, hypertrophic scars stay confined within the wound and ultimately regress. ${ }^{40}$ In studies devoted solely to hypertrophic and keloid scarring, it is stated that these are the greatest challenges that post-burn patients face, which significantly reduces the quality of life of the burn patient. ${ }^{40,41}$ According to Goel and Shrivastava's study, post-burn scars may be mature/ immature, stable/unstable and depigmented/hyperpigmented, but regardless of the nature, they are inevitable after burn injury. ${ }^{37}$ Another study concludes that pathological scars, consisting of hypertrophic scars, hypertrophic scars with contractures and pure contractures, have an overall prevalence of $77 \%{ }^{38}$

Contracture development is a phenomenon in which the skin contracts over the wound to reduce its exposure site. ${ }^{37}$ In a recent study it was found that contracture severity mainly depends on the size of burn injury and length of hospital stay. ${ }^{42}$ Development of this post-burn complication is a common finding among burn patients in Pakistan, as is documented in Saaiq et al's study. ${ }^{43}$ According to their study, there is a high prevalence due to inadequate initial management of burn wounds such as lack of initiation of appropriate surgery, physiotherapy and antideformity splinting, all leading to early contracture development. ${ }^{43}$ With regards to chronic inflammation and metabolic changes in post-burn patients, Jeschke et al's study displayed the persistence of these physiological reactions as long as three years after the initial burn injury. ${ }^{44}$ Cytokines, particularly interleukin (IL)-6, IL-8, G-CSF, MCP-1 and acute-phase proteins, are considerably increased in burn patients during admission as well as after discharge. ${ }^{44}$ In another study, it was ascertained that burn patients stay in a state of chronic inflammatory response..$^{45}$ 
Muscle wasting is defined as a loss of at least $5-10 \%$ of the muscle mass; it is a common physiological complication in burn patients, occurring due to hyper-metabolism and altered protein kinetics such as increased protein breakdown and decreased protein synthesis. ${ }^{46}$ Managing post-burn hyper-metabolism is essential in decreasing burn-related muscle catabolism. ${ }^{46}$ According to Hart et al.'s study, a larger burn wound area, increased weight of the patient and a delay in surgery increases the risk of muscle catabolism. ${ }^{47}$ In Williams et al's study, it was established that increased production of catecholamines in burn patients resulted in the development of severe cardiac stress consisting of elevated heart rate, stroke volume, cardiac work, rate pressure product, myocardial oxygen consumption and cardiac index; these derailed values lasted as long as two years after the burn injury. ${ }^{48}$

Hypothermia is also an important physiological complication in burn patients due to loss of skin which is the body's main temperature regulator. ${ }^{49}$ Some of the factors affecting hypothermia in burn patients are the TBSA of the burn injury, anaesthesia and surgery duration. ${ }^{49}$ Burn patients presenting with hypothermia have an increased risk of mortality. ${ }^{50}$ Table 1 summarises the complications in post-burn patients.

\section{Pain}

According to Gauffin et al's study, one third of the burn patients still felt pain 2-7 years after the initial burn injury. This affected the patients' general activity, mood, work and health related quality of life as measured by the EuroQol five-dimensional instrument..$^{51}$ Burn pain is affected by factors such as TBSA and the location of the burn. The severity does not significantly depend on gender, age or time of injury. ${ }^{51}$ Treatment procedures themselves also give rise to severe pain which affects successful rehabilitation after discharge and also increases the patients' anxiety levels. ${ }^{52}$

\section{Infection}

According to two different studies, infection is a major complication in hospitalised burn patients, that is influenced by the length of hospital stay, decreased immunity, the number of catheters inserted and TBSA of burn injury.53,54 The mechanism of this phenomenon is that thermal energy in burns induces a state of immunosuppression which leads to increased susceptibility to infections. ${ }^{55}$ In Öncül et al's study, nearly half of all burn wounds cultured positive for microorganisms such as Pseudomonas aeruginosa, Staphylococcus epidermidis, methicillin- sensitive strains of Staphylococcus, Enterococcus and Escherichia coli. ${ }^{53}$ In a recent study conducted in Pakistan, it was found that children are most afflicted due to comparatively decreased immunity and resilience. ${ }^{56}$ Post-burn infections, rather than the burn injury itself, may be a cause of mortality in burn patients. ${ }^{57}$ In another study conducted in Pakistan, sepsis was the most common cause of death in burn patients. ${ }^{58}$

In Pakistan, the topic of burns is under-researched and basic knowledge about complications that are bound to arise in burn patients after they have been discharged and treated is even rarer. ${ }^{2}$ Countless studies on epidemiology and hospital stay management have been reported, however, little information has been compiled about the physiological and psychological complications of burns which play a major role in effective rehabilitation of patients. This literature review provides a concise framework of the main complications that occur in burn patients. Mental health screening and early intervention in burn patients is recommended along with burn preventive sessions. ${ }^{59}$ Furthermore, there is a pressing need to enhance the development of rehabilitation services. The scarcity of burn rehabilitation centres in Pakistan supports the importance of this study. The already existing units should be fully functioning with international protocols. Consistent follow-up in multidisciplinary burn clinics is suggested as this is a predictor of better long-term results and social adjustments. It is hoped that through this review the plight of burn patients and the importance of their rehabilitation can be highlighted.

\section{Conclusion}

This review summarises various psychological and physiological complications in burn patients and reveals a scarcity of research on the prevalence and impact of long-term burn complications in Pakistan. Lack of rehabilitative services and the high rate of post-burn complications (depression, PTSD, anxiety, scarring and contractures are most prevalent) in Pakistan have been highlighted. Rehabilitation of burn patients should be a continuation of active treatment and should begin from the day of admission to reduce morbidity and improve the quality of life of burn patients.

\section{AUTHORS' CONTRIBUTION}

MeBA and MaBA took part in designing, drafting and revising the review. MeBA and MaBA were responsible for data collection and analysis of the data. Both authors approved the final version of the manuscript. 


\section{References}

1. World Health Organization. Fact sheets Burns 2018. From: https://www.who.int/news-room/fact-sheets/detail/burns Accessed: Mar 2021.

2. Siddiqui E, Zia N, Feroze A, Awan S, Ali A, Razzak J, et al. Burn injury characteristics: Findings from Pakistan National Emergency Department Surveillance Study. BMC Emerg Med 2015; 15:S5. https://doi.org/10.1186/1471-227X-15-S2-S5.

3. Afzal I, Naz R, Afzal MK, Mughal MI. Epidemiology and mortality of burns in Karachi. Med Forum 2014; 25:36-41.

4. Anwer MO, Rauf MU, Chishti N, Anwer S. Etiology and characteristics of burn injuries in patients admitted at Burns Center, Civil Hospital Karachi. Indian J Burns 2016; 24:36-40. https:// doi.org/10.4103/0971-653X.195535.

5. Ahmed A, Asad S, Khan R, Ibrahim M, Siddique M. Epidemiology of burns and its relation with morbidity and mortality in Ayub teaching hospital. Pak J Surg 2016; 32:156-61.

6. Mehsud R. In Pakistan, shortage of burn centers haunts victims. From: www.newslens.pk/in-pakistan-shortage-of-burn-centers -haunts-victims Accessed: Mar 2021.

7. PPI. Slow burn - lack of burn centers leaves Sindh in limbo. From: www.pakistantoday.com.pk/2015/03/17/slow-burn-lackof-burns-centres-leaves-sindh-in-limbo/ Accessed: Mar 2021.

8. Dawn. No burns centre in KP. From: www.dawn.com/news/ 1343960 Accessed: Mar 2021

9. Ousat A. Dearth of burn units hurting Punjab. From: www. tribune.com.pk/story/1632480/treatment-facility-dearthburn-units-hurting-punjab Accessed: Mar 2021.

10. World Health Organization. Overview of rehabilitation services in health system perspective: Rehabilitation 2030: A call for action. From: who.int/disabilities/care/1130-Pakistan. pdf Accessed: Mar 2021.

11. Ali MB, Ali MB. Burns Awareness Day - Letter To Editors. J Pak Med Assoc 2019; 69:605.

12. Ter Smitten MH, de Graaf R, Van Loey NE. Prevalence and comorbidity of psychiatric disorders 1-4 years after burn. Burns 2011; 37:753-61. https://doi.org/10.1016/j.burns.2010.12.018.

13. Ali H, Pervaiz M. Depression in adults post burn injury: A descriptive study conducted in the burn centre of a tertiary care hospital in Karachi. Ann Burns Fire Disasters 2019; 32:33-6.

14. Ullrich PM, Askay SW, Patterson DR. Pain, depression, and physical functioning following burn injury. Rehabil Psychol 2009; 54:211-16. https://doi.org/10.1037/a0015613.

15. Williams EE, Griffiths TA. Psychological consequences of burn injury. Burns 1991; 17:478-80. https://doi.org/10.1016/03054179(91)90075-r.

16. Shakespeare V. Effect of small burn injury on physical, social and psychological health at 3-4 months after discharge. Burns 1998; 24:739-44. https://doi.org/10.1016/S0305-4179(98)00098-9.

17. Jain M, Khadilkar N, De Sousa A. Burn-related factors affecting anxiety, depression and self-esteem in burn patients: An exploratory study. Ann Burns Fire Disasters 2017; 30:30-4.

18. Van Loey NE, Van Son MJ. Psychopathology and psychological problems in patients with burn scars: Epidemiology and management. Am J Clin Dermatol 2003; 4:245-72. https://doi.org/10.216 5/00128071-200304040-00004.

19. Waqas A, Raza N, Zahid T, Rehman A, Hamid T, Hanif A, et al. Predictors of post-traumatic stress disorder among burn patients in Pakistan: The role of reconstructive surgery in post-burn psychosocial adjustment. Burns 2018; 44:620-5. https://doi. org/10.1016/j.burns.2017.09.012.

20. Bibi A, Kalim S, Khalid MA. Post-traumatic stress disorder and resilience among adult burn patients in Pakistan: A cross-sectional study. Burns Trauma 2018; 6:8. https://doi.org/10.1186/s41038018-0110-7.
21. Giannoni-Pastor A, Eiroa-Orosa FJ, Fidel Kinori SG, Arguello JM, Casas M. Prevalence and predictors of posttraumatic stress symptomatology among burn survivors: A systematic review and meta-analysis. J Burn Care Res 2016; 37:e79-89. https:// doi.org/10.1097/BCR.0000000000000226.

22. Roca RP, Spence RJ, Munster AM. Posttraumatic adaptation and distress among adult burn survivors. Am J Psychiatry 1992; 149:1234-8. https://doi.org/10.1176/ajp.149.9.1234.

23. Sadeghi-Bazargani H, Maghsoudi H, Soudmand-Niri M, Ranjbar F, Mashadi-Abdollahi H. Stress disorder and PTSD after burn injuries: A prospective study of predictors of PTSD at Sina Burn Center, Iran. Neuropsychiatr Dis Treat 2011; 7:425-9. https:// doi.org/10.2147/NDT.S23041.

24. El hamaoui Y, Yaalaoui S, Chihabeddine K, Boukind E, Moussaoui D. Post-traumatic stress disorder in burned patients. Burns 2002; 28:647-50. https://doi.org/10.1016/s0305-4179(02)00100-6.

25. Boeve SA, Aaron LA, Martin-Herz SP, Peterson A, Cain V, Heimbach DM, et al. Sleep disturbance after burn injury. J Burn Care Rehabil 2002; 23:32-8. https://doi.org/10.1097/00004630200201000-00007.

26. Lee AF, Ryan CM, Schneider JC, Kazis LE, Li NC, Rose M, et al. Quantifying risk factors for long-term sleep problems after burn injury in young adults. J Burn Care Res 2017; 38:e510-20. https://doi.org/10.1097/bcr.0000000000000315

27. Varney NR, Ju D, Shepherd JS, Kealey GP. Long-term neuropsychological sequelae of severe burns. Arch Clin Neuropsychol 1998; 13:737-49. https://doi.org/10.1016/S0887-6177(98)00011-0.

28. Andreasen NJ. Neuropsychiatric complications in burn patients. Int J Psychiatry Med 1974; 5:161-71. https://doi.org/10.2190/ FATV-K0DW-12M7-J9BH.

29. Kornhaber R, Childs C, Cleary M. Experiences of guilt, shame and blame in those affected by burns: A qualitative systematic review. Burns 2018; 44:1026-39. https://doi.org/10.1016/j. burns.2017.11.012.

30. Onarheim H, Vindenes HA. High risk for accidental death in previously burn-injured adults. Burns 2005; 31:297-301. https://doi.org/10.1016/j.burns.2004.10.010.

31. Kimmo T, Jyrki V, Sirpa AS. Health status after recovery from burn injury. Burns 1998; 24:293-8. https://doi.org/10.1016/ S0305-4179(98)00007-2.

32. Noronha DO, Faust J. Identifying the variables impacting postburn psychological adjustment: A meta-analysis. J Pediatr Psychol 2007; 32:380-91. https://doi.org/10.1093/jpepsy/jsl014.

33. Waqas A, Naveed S, Bhuiyan MM, Usman J, Inam-Ul-Haq A, Cheema SS. Social support and resilience among patients with burn injury in Lahore, Pakistan. Cureus 2016; 8:e867. https:// doi.org/10.7759/cureus.867.

34. Rosenbach C, Renneberg B. Positive change after severe burn injuries. J Burn Care Res 2008; 29:638-43. https://doi. org/10.1097/BCR.0b013e31817de275.

35. Carver CS, Scheier MF, Weintraub JK. Assessing coping strategies: A theoretically based approach. J Pers Soc Psychol 1989; 56:267-83. https://doi.org/10.1037/0022-3514.56.2.267.

36. Fong J. A study of self-monitoring processes and coping behaviour in burns victims. Burns 1997; 23:S8-11. https://doi. org/10.1016/S0305-4179(97)90094-2.

37. Goel A, Shrivastava P. Post-burn scars and scar contractures. Indian J Plast Surg 2010; 43:S63-71. https://doi.org/10.410 3/0970-0358.70724.

38. Gangemi EN, Gregori D, Berchialla P, Zingarelli E, Cairo M, Bollero D, et al. Epidemiology and risk factors for pathologic scarring after burn wounds. Arch Facial Plast Surg 2008; 10:93-102. https://doi.org/10.1001/archfaci.10.2.93.

39. Lawrence JW, Mason ST, Schomer K, Klein MB. Epidemiology and impact of scarring after burn injury: A systematic review of the literature. J Burn Care Res 2012; 33:136-46. https://doi. org/10.1097/BCR.0b013e3182374452. 
40. Seifert O, Mrowietz U. Keloid scarring: Bench and bedside. Arch Dermatol Res 2009; 301:259-72. https://doi.org/10.1007/ s00403-009-0952-8.

41. Finnerty CC, Jeschke MG, Branski LK, Barret JP, Dziewulski P, Herndon DN. Hypertrophic scarring: The greatest unmet challenge after burn injury. Lancet 2016; 388:1427-36. https:// doi.org/10.1016/S0140-6736(16)31406-4.

42. Godleski M, Lee AF, Goverman J, Herndon DN, Suman OE, Kowalske KJ, et al. Quantifying contracture severity at hospital discharge in adults: A burn model system national database study. J Burn Care Res 2018; 39:604-11. https://doi.org/10.1093/ jbcr/irx027.

43. Saaiq M, Zaib S, Ahmad S. The menace of post-burn contractures: A developing country's perspective. Ann Burns Fire Disasters 2012; 25:152-8.

44. Jeschke MG, Gauglitz GG, Kulp GA, Finnerty CC, Williams FN, Kraft R, et al. Long-term persistance of the pathophysiologic response to severe burn injury. PLoS One 2011; 6:e21245. https://doi.org/10.1371/journal.pone.0021245.

45. Greenhalgh DG, Saffle JR, Holmes JH 4th, Gamelli RL, Palmieri TL, Horton JW, et al. American Burn Association Consensus Conference to define sepsis and infection in burns. J Burn Care Res 2007; 28:776-90. https://doi.org/10.1097/BCR.0b013e318 1599 bc9.

46. Pereira C, Murphy K, Jeschke M, Herndon DN. Post burn muscle wasting and the effects of treatments. Int J Biochem Cell Biol 2005; 37:1948-61. https://doi.org/10.1016/j.biocel.2005.05.009.

47. Hart DW, Wolf SE, Chinkes DL, Gore DC, Mlcak RP, Beauford RB, et al. Determinants of skeletal muscle catabolism after severe burn. Ann Surg 2000; 232:455-65. https://doi.org/10.1097/000 00658-200010000-00001.

48. Williams FN, Herndon DN, Suman OE, Lee JO, Norbury WB, Branski LK, et al. Changes in cardiac physiology after severe burn injury. J Burn Care Res 2011; 32:269-74. https://doi. org/10.1097/BCR.0b013e31820aafcf.
49. Boorom JA. Heat loss in burn patients. AORN J 1973; 17:80-5. https://doi.org/10.1016/S0001-2092(07)60305-6.

50. L. Trembley A, Page D. Are we keeping our burn patients warm enough? JEMS 2014. From: www.jems.com/2014/09/15/arewe-keeping-our-burn-patients-warm-en/ Accessed: Mar 2021.

51. Gauffin E, Öster C, Sjöberg F, Gerdin B, Ekselius L. Health-related quality of life (EQ-5D) early after injury predicts long-term pain after burn. Burns 2016; 42:1781-8. https://doi.org/10.10 16/j.burns.2016.05.016

52. Deniz S, Arslan S. Pain and Anxiety in Burn Patients. Int J Caring Sci 2017; 10:1723-7.

53. Öncül O, Öksüz S, Acar A, Ülkür E, Turhan V, Uygur F, et al. Nosocomial infection characteristics in a burn intensive care unit: Analysis of an eleven-year active surveillance. Burns 2014; 40:835-41. https://doi.org/10.1016/j.burns.2013.11.003.

54. Appelgren P, Björnhagen V, Bragderyd K, Jonsson CE, Ransjö U. A prospective study of infections in burn patients. Burns 2002; 28:39-46. https://doi.org/10.1016/S0305-4179(01)00070-5.

55. Church D, Elsayed S, Reid O, Winston B, Lindsay R. Burn wound infections. Clin Microbiol Rev 2006; 19:403-34. https:// doi.org/10.1128/CMR.19.2.403-434.2006.

56. Uddin MN, Jabeen B, Saadat Mehmood M, Rizwan M. Characterization of isolated bacteria from burn patients and its susceptibility against different antibiotics in district Swat. Pure Appl Biol 2018; 7:121-32. https://doi.org/10.19045/bsp ab.2018.70015.

57. Krishnan P, Frew Q, Green A, Martin R, Dziewulski P. Cause of death and correlation with autopsy findings in burns patients. Burns 2013;39:583-8. https://doi.org/10.1016/j.burns.2012.09.017.

58. Chaudhry IA. Burns: Frequency and mortality related to various age groups. J Surg Pakistan 2009; 14:67-71

59. Idrees S, Gul I, Faize FA, Akhtar M. Psychological reactions, social support, and coping styles in Pakistani female burn survivors. J Burn Care Res 2017; 38:e934-43. https://doi.org/10.1097/ BCR.0000000000000525. 